\title{
Endoscopic ultrasound-guided fine-needle marking of a small pancreatic tumor
}

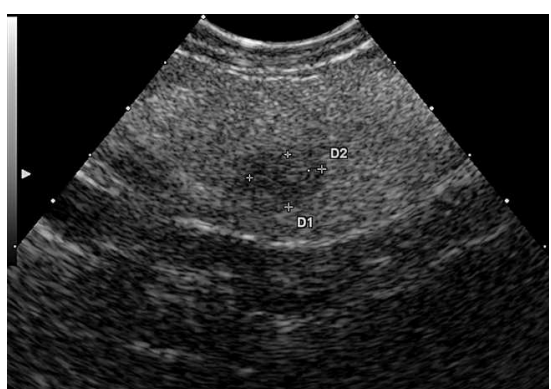

Fig. 1 Endoscopic ultrasound (EUS) shows a 6-mm hypoechoic tumor in the tail of the pancreas.

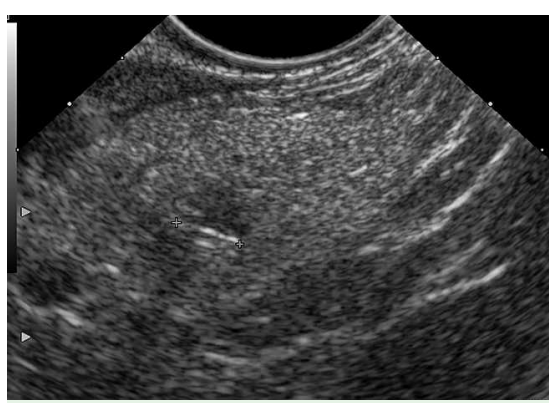

Fig. 3 The silver pin within the tumor is seen on EUS as a linear, hyperechoic structure with an acoustic shadow.

We report a case of endoscopic-ultrasound-guided fine-needle marking (EUSFNM) of a $6-\mathrm{mm}$ pancreatic tumor. The patient was suspected of having pancreatitis, but instead an isolated and hypoechoic lesion was detected in the tail of the pancreas ( $\bullet$ Fig. 1).

EUS-guided fine-needle aspiration (FNA) biopsy was suggestive of malignant cells, and surgery was planned. In order to facilitate the intraoperative detection of the lesion, EUS-FNM of the tumor was performed 18 days preoperatively with a specially manufactured silver pin. The pin $(5 \times 0.8 \mathrm{~mm})$ was made to fit into a 19-gauge needle. Following manual loading of the pin into the tip of the needle under sterile conditions ( $\bullet$ Fig. 2), the lumen was sealed with sterile lidocaine gel to prevent dislocation of the pin.

The needle was inserted into the tumor under EUS guidance, and the stylet was reintroduced to push the pin into the tumor. The position of the pin was easily verified as a hyperechoic linear structure with a shadow ( $\bullet$ Fig. 3 ).

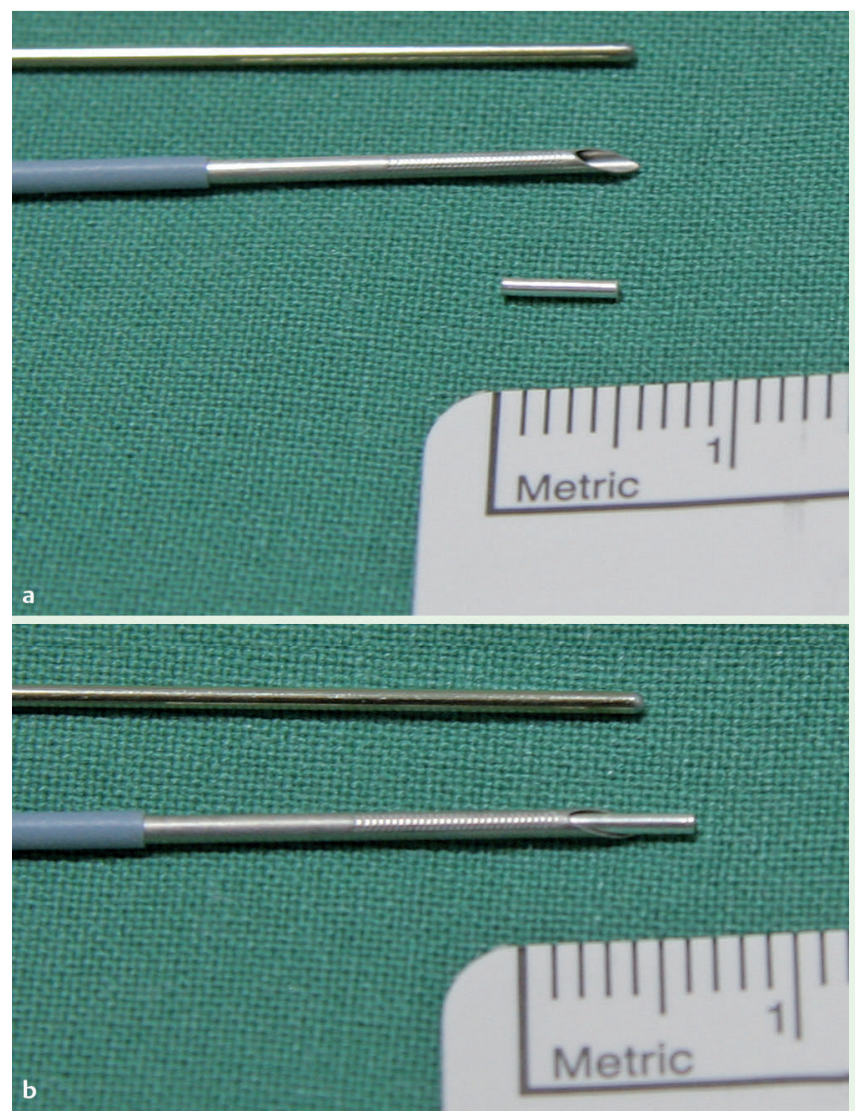

Fig. 2 a Stylet, silver pin, and 19-gauge needle. $\mathbf{b}$ Pin fitting inside the hollow needle.

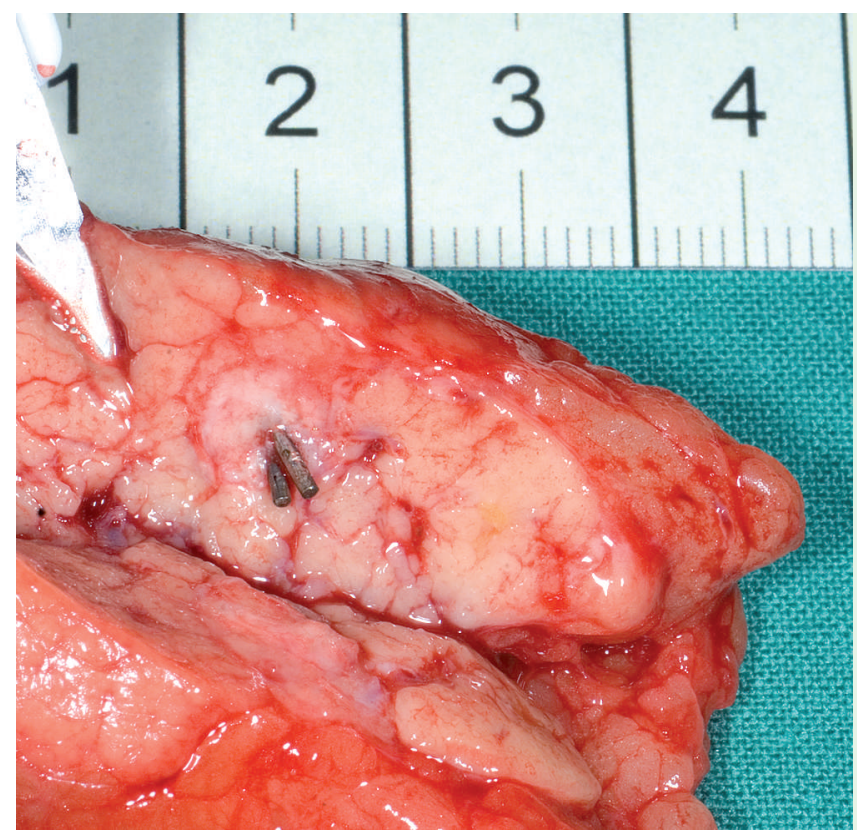

Fig. 4 Both pins identified inside the tumor.

Two pins were placed in the tumor, and no antibiotics were given. There were no signs of complications in the period before surgery.
The pins were easily located using laparoscopic and intraoperative ultrasound. The exact position within the tumor was con- 
firmed by splitting of the specimen (๑ Fig. 4).

The postoperative course was uneventful. Histological examination revealed a nonfunctional glucagonoma without any histological reaction to the pin.

EUS is particularly useful in the assessment of small pancreatic tumors missed by other imaging techniques $[1,2]$. EUSguided tumor injection with dyes has been described, but dyes dilute over time and distance, making it necessary to perform the procedure as near in time to surgery as possible $[3,4]$.

EUS-guided injection and antitumor therapy are evolving rapidly, and EUS-FNM follows the same principle [5]. EUS-FNM may be performed during the primary EUS and independently of surgical planning. The pin is a radiopaque and ultrasonically visible marker, and may thus facilitate intraoperative location of the tumor and reduce surgical time. However, more data are needed to establish the safety and clinical utility of this new marking technique.

\section{Endoscopy_UCTN_Code_TTT_1AS_2AD \\ Endoscopy_UCTN_Code_TTT_1AS_2AF}

\section{H. Larsen, C. W. Fristrup,}

\section{B. Mortensen}

Centre for Surgical Ultrasound, Department of Surgical Gastroenterology, Odense University Hospital, DK-5000, Odense C, Denmark

\section{References}

1 Soriano A, Castells A, Ayuso C et al. Preoperative staging and tumor resectability assessment of pancreatic cancer: prospective study comparing endoscopic ultrasonography, helical computed tomography, magnetic resonance imaging, and angiography. Am J Gastroenterol 2004; 99: 492 - 501

2 Anderson MA, Carpenter S, Thompson NW et $a l$. Endoscopic ultrasound is highly accurate and directs management in patients with neuroendocrine tumors of the pancreas. Am J Gastroenterol 2000; 95: 2271 - 2277
3 Ashida R, Yamao K, Okubo K et al. Indocyanine green is an ideal dye for endoscopic ultrasound-guided fine-needle tattooing of pancreatic tumors. Endoscopy 2006; 38: 190- 192

4 Gress FG, Barawi M, Kim D, Grendell JH. Preoperative localization of a neuroendocrine tumor of the pancreas with EUS-guided fine needle tattooing. Gastrointest Endosc 2002; 55: $594-597$

5 Chang KJ. EUS-guided fine needle injection (FNI) and anti-tumor therapy. Endoscopy 2006; 38 (Suppl 1): $88-93$

\section{Bibliography}

DOI $10.1055 / \mathrm{s}-0029-1214699$

Endoscopy 2009; 41: E175-E176

(c) Georg Thieme Verlag KG Stuttgart · New York . ISSN 0013-726X

\section{Corresponding author}

\section{H. Larsen, MD}

Centre for Surgical Ultrasound

Department of Surgical Gastroenterology

Odense University Hospital

DK-5000 Odense C

Denmark

mhl@dadlnet.dk 